\title{
Assessment of nocturnal aerosol optical depth from lunar photometry at the Izaña high mountain observatory
}

\author{
África Barreto ${ }^{1,2,3}$, Roberto Román ${ }^{4,5}$, Emilio Cuevas ${ }^{3}$, Alberto J. Berjón ${ }^{2}$, A. Fernando Almansa ${ }^{1,2,3}$, \\ Carlos Toledano $^{2}$, Ramiro González ${ }^{2}$, Yballa Hernández ${ }^{3}$, Luc Blarel ${ }^{6}$, Philippe Goloub ${ }^{6}$, Carmen Guirado ${ }^{2,3}$, and \\ Margarita Yela ${ }^{7}$ \\ ${ }^{1}$ Cimel Electronique, Paris, France \\ ${ }^{2}$ Grupo de Óptica Atmosférica, Universidad de Valladolid, Valladolid, Spain \\ ${ }^{3}$ Izaña Atmospheric Research Center, State Meteorological Agency of Spain (AEMET), Santa Cruz de Tenerife, Spain \\ ${ }^{4}$ Department of Applied Physics, University of Granada, Granada, Spain \\ ${ }^{5}$ Andalusian Institute for Earth System Research, IISTA-CEAMA, University of Granada, Junta de Andalucía, Granada, \\ Spain \\ ${ }^{6}$ Laboratoire d'Optique Atmosphérique (LOA), Université de Lille, Villeneuve d'Ascq, France \\ ${ }^{7}$ Instrumentation and Atmospheric Research Department, National Institute for Aerospace Technology (INTA), Madrid, Spain
}

Correspondence to: Emilio Cuevas (ecuevasa@ aemet.es)

Received: 31 December 2016 - Discussion started: 26 January 2017

Revised: 17 July 2017 - Accepted: 18 July 2017 - Published: 21 August 2017

\begin{abstract}
This work is a first approach to correct the systematic errors observed in the aerosol optical depth (AOD) retrieved at nighttime using lunar photometry and calibration techniques dependent on the lunar irradiance model. To this end, nocturnal AOD measurements were performed in 2014 using the CE318-T master Sun-sky-lunar photometer (lunar Langley calibrated) at the Izaña high mountain observatory. This information has been restricted to 59 nights characterized as clean and stable according to lidar vertical profiles. A phase angle dependence as well as an asymmetry within the Moon's cycle of the Robotic Lunar Observatory (ROLO) model could be deduced from the comparison in this 59-night period of the CE318-T calibration performed by means of the lunar Langley calibration and the calibration performed every single night by means of the common Langley technique. Nocturnal AOD has also been compared in the same period with a reference AOD based on daylight AOD extracted from the AErosol RObotic NETwork (AERONET) at the same station. Considering stable conditions, the difference $\triangle \mathrm{AOD}_{\text {fit }}$, between $\mathrm{AOD}$ from lunar observations and the linearly interpolated AOD (the reference) from daylight data, has been calculated. The results show that $\triangle \mathrm{AOD}_{\text {fit }}$ values are strongly affected by the Moon phase and zenith angles. This dependency has been parameterized using an em-
\end{abstract}

pirical model with two independent variables (Moon phase and zenith angles) in order to correct the AOD for these residual dependencies. The correction of this parameterized dependency has been checked at four stations with quite different environmental conditions (Izaña, Lille, Carpentras and Dakar) showing a significant reduction of the AOD dependence on phase and zenith angles and an improved agreement with daylight reference data. After the correction, absolute AOD differences for day-night-day clean and stable transitions remain below 0.01 for all wavelengths.

\section{Introduction}

Aerosols can significantly influence the climate in several ways: through aerosol-radiation and aerosol-cloudprecipitation interactions (Foster et al., 2007; IPCC, 2013). This fact has motivated notable efforts in atmospheric sciences envisaged to increase the understanding of the role played by aerosols in the global climate balance.

Aerosol optical depth (AOD) is a valuable parameter accounting for aerosol load in the atmosphere because it is a measure of the extinction of the solar beam by absorption and scattering processes caused by aerosols. Sun pho- 
tometry provides useful information to retrieve columnar aerosol optical and microphysical properties with an excellent spatial coverage but with a lack of vertical resolution (Holben et al., 1998, 2001; Eck et al., 1999, 2009, 2010). A good example of the spatial extent of Sun photometry techniques is the widespread ground-based AErosol RObotic NETwork (AERONET) (Holben et al., 1998) and its federated networks, including hundreds of stations globally distributed. However, aerosols at nighttime have been studied to a much lesser extent (Barreto et al., 2013a, b; Baibakov et al., 2015). There is a growing interest in studying the diurnal dynamics and evolution of atmospheric aerosols (PérezRamírez et al., 2012a) as well as understanding the nucleating role of aerosols and their net radiative effects (Baibakov et al., 2015). Therefore, new technological developments try to fill the night-period gaps in AOD time series. As Baibakov et al. (2015) pointed out, star and Moon photometry have arisen as plausible solutions to this problem. The star photometer technique (Leitener et al., 1995; Pérez-Ramírez et al., 2015; Baibakov et al., 2015) has been revealed as a useful tool to infer aerosol information during the night period. However, infrastructure and logistic constraints still represent an important limitation for the operational use of stellar measurements, especially for global networks such as AERONET. Alternatively, Moon photometry is a technique that can be implemented more easily, and at a lower cost, in an operational way (Barreto et al., 2016). Nevertheless, the Moon photometry technique is still affected by notable limitations. Despite the Moon being our nearest celestial neighbor, our knowledge about its spectral irradiance is far from being as precise as the spectra from the Sun or bright stars like Vega (Cramer et al., 2013). The main important obstacle in Moon photometry is the fact that the Moon is a variable reflector of sunlight and, as a result, it is a highly variable source of visible light (Miller et al., 2012).

Pioneering works in lunar photometry were developed by Esposito et al. (1998), Esposito et al. (2003), Berkoff et al. (2011) and Barreto et al. (2013a, b). Recently, Barreto et al. (2016) presented the new photometer CE318-T which combines the features of the extensively used CE318 Cimel Sun photometer standard model in the AERONET network, with the lunar photometer prototype previously presented in Barreto et al. (2013a, b). The higher precision of this new instrument compared to the previous versions of Sun and Moon photometers and its ability to monitor atmospheric aerosols in a diurnal cycle have made it a suitable instrument to replace the CE318-AERONET reference instrument.

As many authors have stated (Berkoff et al., 2011; Barreto et al., 2013a, b, 2016), a precise Moon irradiance model is mandatory in Moon photometry to take the continuous change of the Moon's brightness over the cycle into account. In this respect, the Robotic Lunar Observatory (ROLO) model, developed by Kieffer and Stone (2005), is the most careful radiometric study on the Moon's brightness to date (Cramer et al., 2013). The ROLO model has recently emerged as a unique tool for Moon photometry (Berkoff et al., 2011; Barreto et al., 2013a, b, 2016) and is an essential part of the calibration process. Although this model provides precise information about the change of the Moon's irradiance with the phase angle $(g)$ and lunar librations, small systematic effects have been found in this model. Lacherade et al. (2013, 2014) and Viticchié et al. (2013) found a small phase angle dependence of the ROLO calibration using the Pleiades Orbital Lunar Observations (POLO) and Meteosat Second Generation (MSG) Spinning Enhanced Visible and Infrared Imager (SEVIRI) solar bands. Cramer et al. (2013) developed a novel apparatus to accurately measure the lunar spectral irradiance with the aim of estimating these systematic effects in the ROLO model. Barreto et al. (2016) used the CE318-T and the ROLO model to retrieve AOD at day- and nighttime at Izaña, a high altitude observatory located at Tenerife (the Canary Islands, Spain). These authors observed an important dependence of the AOD uncertainty with phase angle and also a faint nocturnal cycle in AOD, indicating a possible dependence of AOD uncertainty on the Moon's zenith $(\theta)$ and phase angles. As these authors stated, the reason for these discrepancies remain unclear, although it is likely to be due to a sum of causes, such as inaccurate instrument calibration, possible systematic errors in the ROLO model, instrumental problems and/or uncertainties in nighttime AOD calculation.

This work is based on all of the previous results to improve the AOD retrieval at nighttime by selecting a set of clean and stable nighttime conditions at Izaña in which daytime AOD data could be considered a good proxy for nocturnal AOD. Clean and stable conditions of days used in this study have been ensured using AERONET daytime data at the station and micropulse lidar version 3 (MPL-3) atmospheric vertical profiles extracted from a nearby coastal station. The main aim of this study is to identify the error sources, thereby trying to experimentally fix some of the problems currently affecting Moon photometry.

Section 2 describes the experiment site, instruments and methods used in this study. A description of the methodology developed to improve nocturnal AOD measurements and the corresponding validation performed at Izaña, as well as in other complementary stations, is presented in Sect. 3. Finally conclusions are shown in Sect. 4.

\section{Measurement site}

\subsection{Test site}

Nocturnal measurements have been carried out at the Izaña Global Atmosphere Watch (GAW) observatory (http://izana. aemet.es), managed by the Izaña Atmospheric Research Center (IARC) from the State Meteorological Agency of Spain (AEMET). The Izaña observatory is a test bed for aerosols and water vapor remote sensing instruments of the World 
Meteorological Organization (WMO) Commission for Instruments and Methods of Observations (CIMO). It is a high mountain station (2373 ma.s.l.) located at Tenerife (the Canary Islands, Spain) at $28^{\circ} 18^{\prime} \mathrm{N}, 16^{\circ} 29^{\prime} \mathrm{W}$. The main features of this station have been extensively described by Rodríguez et al. (2011), Cuevas et al. (2013), Guirado (2014) and Cuevas et al. (2015).

The station is characterized by NW subsiding air from the descending branch of the Hadley cell, resulting in a strong temperature inversion normally located below the altitude of the station (800 to $1500 \mathrm{~m}$ a.s.l.). This structure usually separates the humid layer, potentially laden with some anthropogenic pollution from lower parts of the island, from the dry and clean troposphere above. Environmental conditions at Izaña make the site quite suitable for aerosol sensor calibrations because of the wide range of AOD values: from AOD at $500 \mathrm{~nm}\left(\mathrm{AOD}_{500}\right)$ below 0.01 under background almostRayleigh conditions to $\mathrm{AOD}_{500}$ above 0.15 under Saharan dust intrusions. Around $85 \%$ of the days present quite stable and low $\mathrm{AOD}_{500}$ values, below 0.15 (Guirado, 2014). Pristine conditions make Izaña a suitable place to calibrate photometers using the Langley method.

\subsection{Instruments}

\subsubsection{CE318-T photometer}

The new Sun-sky-lunar multiband photometer (CE318-T) has recently been presented in Barreto et al. (2016) as an advanced system which combines the features of the Sun photometer CE318-N, extensively used as a reference instrument in the AERONET network (Holben et al., 1998), with the lunar photometer prototype CE318-U presented in Barreto et al. (2013a, b). The new CE318-T photometer is capable of measuring Sun, Moon and sky radiances at an approximate field of view of $1.29^{\circ}$ at eight nominal wavelengths of 1020, 937, 870, 675, 500, 440, 380 and $340 \mathrm{~nm}$, using a silicon photodiode detector, as well as two additional measurements at 1020 and $1640 \mathrm{~nm}$ using an InGaAs detector. The silicon $1020 \mathrm{~nm}$ channel has been temperature corrected following the methodology presented in Holben et al. (1998). The UV spectral bands do not allow an accurate AOD retrieval at night due to the low lunar signal in this wavelength range. The CE318-T master used in the present study has been calibrated by means of the lunar Langley calibration method presented in Barreto et al. (2013a). Cloud screening of nighttime AOD data has been performed by visual inspection and using the triplet criterion presented in Barreto et al. (2016).

\subsubsection{MPL-3 lidar}

Vertical range-corrected signal profiles from the MPL-3 lidar installed at Santa Cruz de Tenerife (Tenerife, Canary Islands, Spain; $28^{\circ} 30^{\prime} \mathrm{N}, 16^{\circ} 12^{\prime} \mathrm{W} ; 52 \mathrm{~m}$ a.s.l.) have been used to check the AOD stability. This instrument contains a solidstate laser system emitting at $532 \mathrm{~nm}$ in full-time continuous mode with a high-pulse repetition rate of $2500 \mathrm{~Hz}$. More details of this system and the on-site maintenance and calibration techniques are described by Campbell et al. (2002) and Welton and Campbell (2002).

\subsection{ROLO model}

Robotic Lunar Observatory (ROLO) model, developed as a part of the USGS- and NASA-funded program for spaceborne calibration, is considered an accurate tool for exoatmospheric lunar spectral irradiance $\left(I_{0}\right)$ estimation for a given position of the observer on the Earth's surface and at a given time (Kieffer and Stone, 2005). This empirically based model provides the Moon's irradiance at 32 wavelengths, with an uncertainty between 5 and $10 \%$ in the absolute scale, using only geometrical variables: the absolute phase angle, the selenographic latitude and longitude of the observer, and the selenographic longitude of the Sun. $I_{0}$ values have been calculated in this work as the convolution of the product of Moon reflectances, calculated using our own implementation of the ROLO model based rigorously on Eq. (10) published in Kieffer and Stone (2005), the solar spectrum given by Wehrli (1986) and the Earth-Moon and Sun-Moon distances, with each of the CE318-T filter responses. The result must be multiplied by the solid angle of the Moon $\left(\sigma_{\mathrm{M}}=6.4177 \times 10^{-5} \mathrm{sr}\right)$ divided by $\pi$, according to Kieffer and Stone (2005). The lunar ephemeris have been extracted using the Navigation and Ancillary Information Facility (NAIF) of the NASA Jet Propulsion Laboratory (https://naif.jpl.nasa.gov/naif/), which uses data of the orbital position of many celestial bodies known as kernels or Spacecraft, Planet, Instrument, C-matrix (pointing) and Events (SPICE) data files. This NAIF SPICE toolkit is freely available at http://naif.jpl.nasa.gov/.

\subsection{AOD retrieval method}

Following Barreto et al. (2013a) and Barreto et al. (2016), AOD at nighttime ( $\tau_{\mathrm{a}, \text { night }}$ ) for a given wavelength, $\lambda$, can be calculated using the following equation:

$\tau_{\mathrm{a}, \text { night }, \lambda}=\frac{\ln \left(\kappa_{\lambda}\right)-\ln \left(\frac{V_{\lambda}}{I_{0, \lambda}}\right)-m_{\mathrm{atm}}(\theta) \cdot \tau_{\mathrm{atm}, \lambda}}{m_{\mathrm{a}}(\theta)}$.

In this expression $\kappa_{\lambda}$ is the calibration constant, $V_{\lambda}$ is the measured voltage, $I_{0, \lambda}$ is the extraterrestrial Moon irradiance given by the ROLO model, $m_{\mathrm{atm}}$ and $\tau_{\mathrm{atm}}$ are the air mass and the optical depth of all atmospheric attenuators with the exception of aerosols (Rayleigh scattering and $\mathrm{O}_{3}$ and $\mathrm{NO}_{2}$ absorption), and $m_{\mathrm{a}}$ is the aerosol air mass. $\theta$ stands for the Moon's zenith angle. Subindex $\lambda$ makes reference to the respective $\lambda$ wavelength. All these terms have been calculated using the AERONET version 2 procedure (http://aeronet. gsfc.nasa.gov/new_web/data_description_AOD_V2.html). 
The calibration constant $\kappa_{\lambda}$ has been calculated by means the lunar Langley method developed by Barreto et al. (2013a). The main equations involved in this method are Eq. (2), derived from the Beer-Lambert-Bouguer law (the basis of the Langley calibration technique described by many authors in Sun photometry, such as Shaw, 1976, 1983; and Holben et al., 1998, among others) and Eq. (3) (the basis of the lunar Langley calibration technique), which defines the calibration constant as the ratio of $V_{0}$ to $I_{0}$.

$\ln \left(V_{\lambda}\right)=\ln \left(V_{0, \lambda}\right)-m(\theta) \cdot \tau_{\lambda}$

$V_{0, \lambda}=I_{0, \lambda} \cdot \kappa_{\lambda}$

Following the error propagation analysis performed by Barreto et al. (2016), the total combined uncertainty on the AOD retrieved using the CE318-T photometer is the sum of the relative uncertainties associated with the instrument calibration, the ROLO model ( $\sim 1 \%$, independent of orbital parameters) and instrumental errors. Only uncertainties related to instrumental errors were expected to be dependent on the Moon's phase angle $(g)$.

\section{Results}

\subsection{Identifying bias in the lunar irradiance model}

A set of 59 nights characterized by pristine and stable AOD conditions at Izaña covering different Moon cycles, from March to December 2014, has been selected in this study. We have ensured stable AOD conditions using ancillary vertical information from the MPL-3 lidar running at the Santa Cruz de Tenerife station. These stable AOD conditions are confirmed by means of the range-corrected signal from the MPL3 lidar at Santa Cruz and the AOD (daytime from AERONET and nighttime from CE318-T, both at $500 \mathrm{~nm}$ ) at Izaña. The AOD stability criterion involves an AOD difference between the $1 \mathrm{~h}$ average AERONET AOD of two consecutive days (sunset versus sunrise) $\leq 0.005$ at $870 \mathrm{~nm}$. The MPL- 3 profiles and the AOD evolution for one Moon cycle in the period 3-17 October 2014 are shown in Fig. 1. AOD is stable in the whole period with the exception of 3-5 and 10 October, and these three nights are discarded from the fitting analysis. AERONET daytime AOD in this period ranges from 0.004 at $1640 \mathrm{~nm}$ to 0.016 at $440 \mathrm{~nm}$.

Nocturnal measurements were performed by means of a master CE318-T installed at the Izaña station. This instrument has been calibrated following the lunar Langley calibration method proposed by Barreto et al. (2013a) (Eqs. 2 and 3). This is a new absolute calibration technique, specifically developed for lunar photometry, which is able to avoid the determination of one different calibration coefficient every night required by the common Langley technique (Eq. 2). It is important to emphasize the Moon's illumination variation inherent to the lunar cycle, which means the $V_{0}$ and $I_{0}$ terms in Eq. (3) are continuously changing, even during the $\sim 2 \mathrm{~h}$ observation time period required to perform the Langley calibration. Even if we discard the $I_{0}$ variation during the Langley period, the extraterrestrial voltages $V_{0}$ should be determined every day, which is not plausible considering the restrictive requirements in terms of atmospheric stability and cloudiness of this calibration technique. In spite of the simplicity of the lunar Langley technique, its accuracy relies on the uncertainty involved in the ROLO model. The uncertainty estimation of the lunar Langley method was performed by Barreto et al. (2016), assuming a relative ROLO accuracy of $\sim 1 \%$, independent of any orbital parameters. As a result, if the existence of some bias in the ROLO model is confirmed, the accuracy of the lunar Langley technique for absolute calibration should be revised.

The CE318-T lunar Langley calibration was performed on three different nights within the 10 Moon-cycle period used in this paper: 13 March, 12 June and 9 October. These three nights were characterized by the Moon's illumination between 93 and $99 \%$, with phase angles $(g)$ between -31 and $19^{\circ}$. Meanwhile, CE318-T Langley calibration was performed on 51 different nights covering phase angles from -94 to $83^{\circ}$.

A comparison of the two absolute calibration techniques, Langley and lunar Langley, has been carried out in this paper. In the case of $\kappa$ 's obtained using the lunar Langley technique, we have calculated the average $I_{0}$ from the ROLO model during the calibration period to obtain the calibration coefficient $\left(V_{0}\right)$. To this end, we have used Eq. (3).

We found nearly stable $I_{0}$ values during the Langley period $(\leq 2 \mathrm{~h})$, with average standard deviations below $1.6 \%$. Relative $V_{0}$ differences with phase angle (Langley versus lunar Langley) are shown in Fig. 2 for the $870 \mathrm{~nm}$ channel. Relative differences $>4 \%$ are observed, especially near full Moon and near waning Moon. Small differences were found for phase angles between -20 and $60^{\circ}(<1 \%)$ and between 20 and $60^{\circ}(<2 \%)$, in addition to an asymmetry of the differences with phase angle (higher differences after full Moon). It is worth mentioning the lunar Langley calibration technique systematically underestimates $V_{0}$ throughout the lunar cycle.

This phase angle dependence of the ROLO model has been also reported by Lacherade et al. $(2013,2014)$ and Viticchié et al. (2013) as well as its asymmetry within the Moon cycle (Lacherade et al., 2013, 2014). Lacherade et al. (2014) found a variation up to $5 \%$ with the phase angle between $\pm 90^{\circ}$, which is the validity range of the ROLO model. These results are in agreement with the relative differences higher than $4 \%$ found in this study.

It is important to highlight that Barreto et al. (2016) considered negligible the contribution of the covariance term in the combined uncertainty of two magnitudes expected to be correlated: $\kappa$ and $I_{0}$. This last assumption, which neglects the effect of possible Moon irradiance uncertainties on calibration, is only valid when considering that there are no relevant systematic errors in the irradiance model. Our results prove 


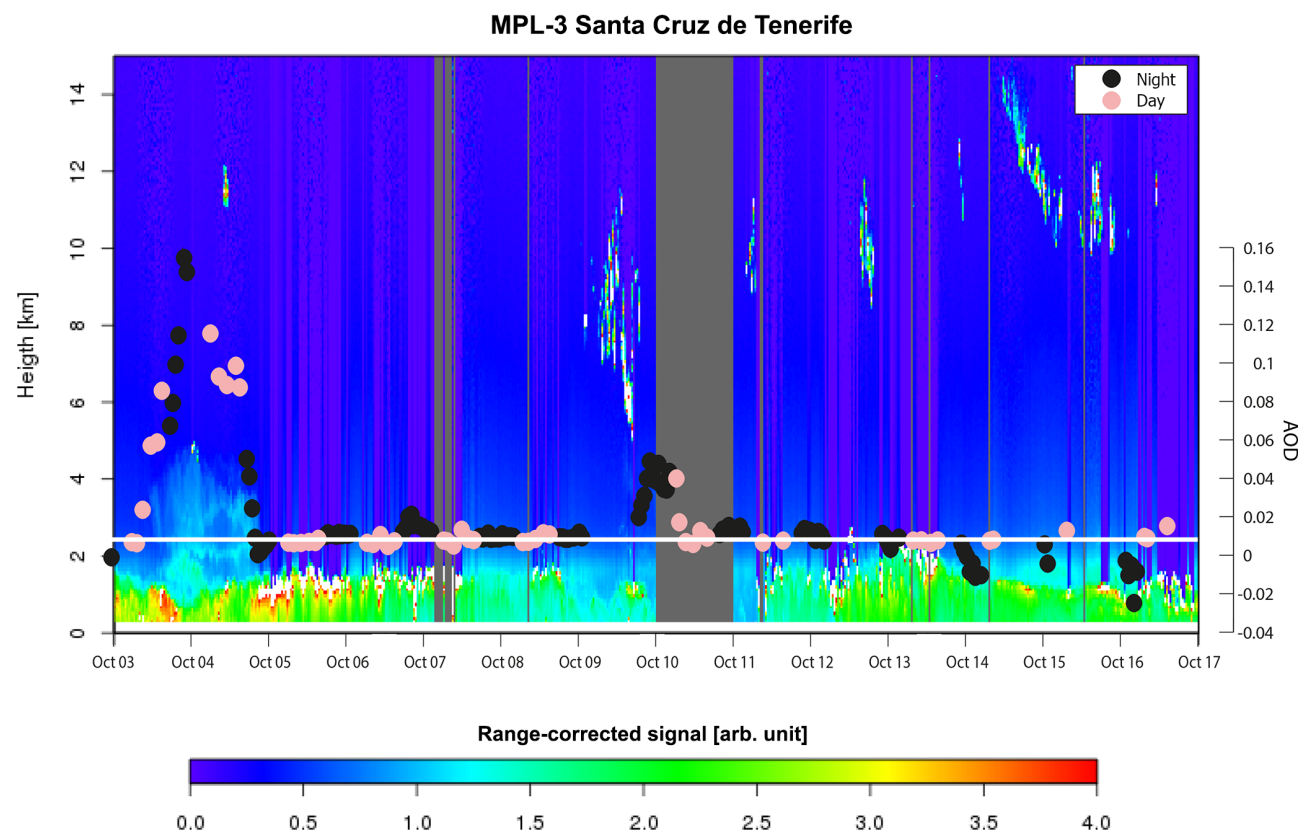

Figure 1. Lidar range-corrected backscattering signal from the MPL-3 installed at Santa Cruz and AOD (at $500 \mathrm{~nm}$ ) evolution (day in pink circles and night in black circles) extracted from the CE318-T installed at Izaña in October 2014. Horizontal white line represents the Izaña observatory altitude.

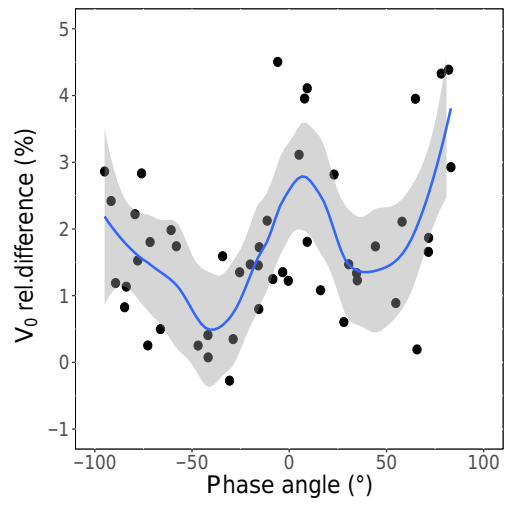

Figure 2. Calibration coefficients $\left(V_{0}\right)$ relative difference $(\%)$ at $870 \mathrm{~nm}$ when Langley and lunar Langley absolute calibration techniques are compared. Smoothing by means of LOESS (locally estimated scatterplot smoothing) is shown with solid line. The shaded areas represent the $95 \%$ confidence interval.

this statement is wrong, and the existence of a bias in the lunar irradiance model must be taken into account in lunar photometry.

\subsection{Correction of artificial AOD variations at nighttime}

Once we have verified the existence of a bias in the lunar irradiance model which introduces calibration and AOD uncertainties dependent on the Moon's phase angle, we propose an empirical correction method for the AOD retrieval at nighttime. This method is exclusively focused on the AOD retrieval and it does not involve any correction to the lunar irradiance model.

We propose an empirical correction based on the use of daytime AOD information as proxy for nocturnal AOD provided aerosol content remains stable. A total of 6997 nighttime AOD measurements corresponding to the same 59 pristine and stable-night period (March to December 2014) in addition to 14575 daylight AOD measurements have been selected in this study. These clean conditions allow us to accurately estimate AOD at nighttime, considering a smooth AOD variation by linear interpolation using AERONET daylight information. AOD differences at nighttime $\left(\triangle \mathrm{AOD}_{\mathrm{fit}}\right)$ are defined through the comparison of the nighttime AOD estimated from linear interpolation using AERONET daylight data $\left(\mathrm{AOD}_{\text {night,interp }}\right)$ and the $\mathrm{AOD}$ obtained directly from nocturnal CE318-T measurements using Eq. (1) $\left(\mathrm{AOD}_{\text {night }}\right)$. Then, $\triangle \mathrm{AOD}_{\text {fit }}$ can be obtained by means the following expression:

$\Delta \mathrm{AOD}_{\text {fit }}=\Delta \mathrm{AOD}_{\text {night,interp }}-\mathrm{AOD}_{\text {night }}$

These differences are displayed in Fig. 3a with asterisks. We observe a clear dependence with the phase angle $(g)$, increasing considerably for higher $g$ values. This dependence is more evident for higher wavelengths and seems somewhat asymmetric (higher differences for positive $g$, namely, after full Moon, especially for the $1020 \mathrm{~nm}$ channel), which is in agreement with the results obtained in Sect. 3.1. We have found the best fit for this dependency $\left(\delta_{g}\right)$ to be a second- 

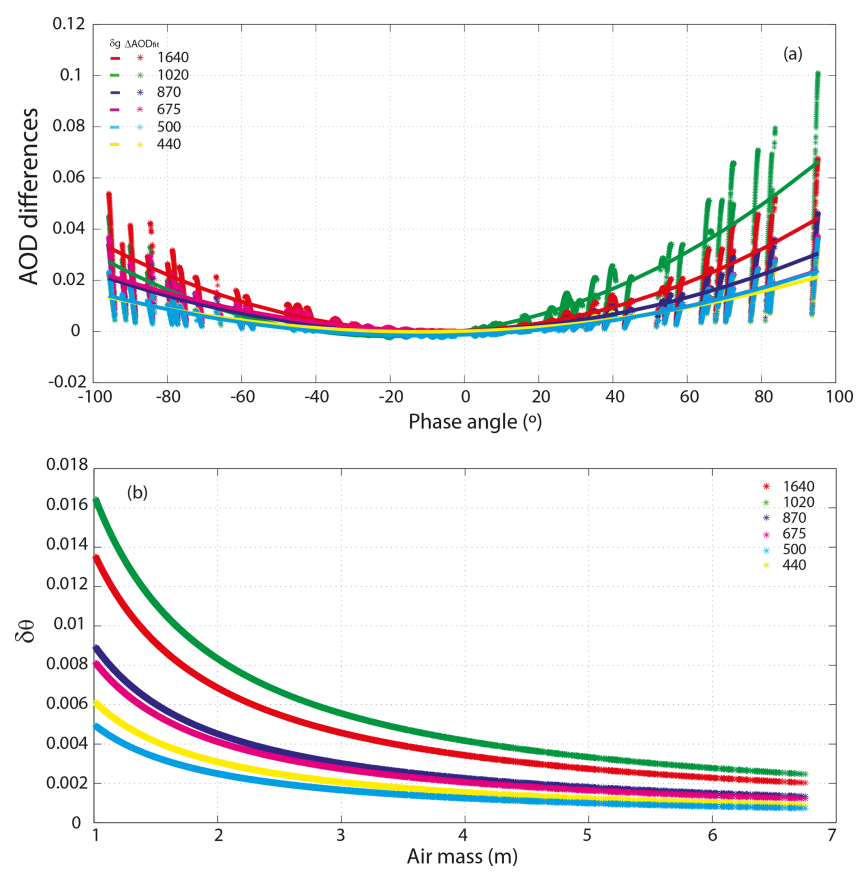

Figure 3. (a) AOD differences between daylight interpolated and nighttime measured values $\left(\triangle \mathrm{AOD}_{\text {fit }}\right.$ with data points) and $\mathrm{AOD}$ differences predicted from the fitting analysis with the Moon's phase angle ( $\delta_{g}$ with colored lines). (b) AOD differences predicted from the fitting analysis with the Moon's zenith angle $\left(\delta_{\theta}\right)$.

order polynomial (Eq. 3), as it is displayed in Fig. 3a with solid lines.

$\delta_{g}(\lambda)=a_{0}(\lambda)+a_{1}(\lambda) \cdot g+a_{2}(\lambda) \cdot g^{2}$

The coefficients $a_{i}$ in Eq. (3) are calculated for each channel centered at $\lambda$. In addition, the presence of a nocturnal cycle on $\triangle \mathrm{AOD}_{\text {fit }}$ is also evident from Fig. 3a. These results are also in agreement with those found by Barreto et al. (2016), who found higher AOD discrepancies with respect to daytime AERONET data for higher phase angles, and a faint nocturnal AOD cycle.

The increasing uncertainty in AOD with $g$ and the asymmetry of this dependence within the Moon cycle can be attributed, at least partially, to the existence of some residuals on the ROLO model, according to the results presented in Sect. 3.1. This effect results in a systematic $g$-dependent AOD error observed in Fig. 3a, with values up to 0.035 before full Moon $(1640 \mathrm{~nm})$ and $>0.06$ after full Moon $(1020 \mathrm{~nm})$, both for the highest phase angles. As Barreto et al. (2016) found, relative uncertainties associated with lunar measurements performed under higher phase angles (low illumination) are about $0.5 \%$ due to a lower signal-to-noise ratio compared with the $0.1 \%$ expected for near-full-Moon conditions. Note that these uncertainties change with $g$. However, this second factor introduces a random error, which we do not expect to introduce any bias in the AOD retrieval process.
The observed AOD cycle at nighttime is similar to the AOD cycle detected by many authors in Sun photometry (Cachorro et al., 2004, 2008a, b) but with an amplitude dependent on $g$. The characteristics of this AOD cycle are expected to be similar to those of Sun photometry: systematic and symmetrical around the lunar noon (Moon at maximum height), with maximum values at lunar noon and vanishing for larger air masses, being independent of AOD. The systematic artificial AOD behavior and the persistence of this feature for different atmospheric conditions indicate that it is not an atmospheric effect nor is it directly related to the ROLO model (ROLO's outputs are not $\theta$ dependent). It is likely produced by a calibration problem caused by the use of a biased ROLO model during calibration. Since the nocturnal calibration is normally performed at high illumination conditions, and AOD is subsequently calculated in these conditions using the ROLO irradiances ( $I_{0}$ 's in Eq. 1), we suspect the possible bias in ROLO is canceled for lower phase angles. However, when calibration constants (independent of Moon) and the $I_{0}$ 's are applied to low illumination conditions in AOD calculation, some $g$-dependent AOD residuals are expected to appear, causing the artificial nocturnal cycle observed in the AOD residuals. Since this systematic effect can be modulated by the inverse of air mass, we propose the inclusion of the effect of zenith angle on AOD difference as a function of $1 / m_{\mathrm{a}}\left(\delta_{\theta}\right.$ in Eq. 4$)$.

$\delta_{\theta}(\lambda)=\frac{\beta_{0}(\lambda)}{m_{\mathrm{a}}(\theta)}$

The coefficient $\beta_{0}$ in Eq. (4) is calculated for each channel centered at $\lambda$. The functional form of this corrective factor against the air mass (not including any dependence on $g$ ) shows that the closer the Moon is to the zenith the higher AOD differences are (Fig. 3b). We have displayed $\delta_{\theta}$ in a whole night at different phase angles and we found an impact of zenith angle on AOD between 0.005 (at $500 \mathrm{~nm}$ ) and 0.016 (at $1020 \mathrm{~nm}$ ), as it is shown in Fig. 4. A similar and symmetrical nocturnal cycle is displayed in the three nights, one near full Moon ( 8 October, $g$ ranging from -9 to $-3^{\circ}$ ) and two nights with low illumination conditions (6 April and 16 October, with $g$ between \pm 93 and $\pm 96^{\circ}$ ), in which approximately half of the Moon's trajectory between rising to setting times is displayed (due to sunlight).

\subsection{Improvement of AOD retrieval at Izaña}

The two effects parameterized in Eqs. (3) and (4) are considered independent. Since these two variables are uncorrelated, we propose a final parameterization based on these two effects: phase angle dependence (quadratic dependence) modulated by zenith angle. This parameterization, for each channel centered at $\lambda$, is presented in Eq. (5), where $\delta_{g, \theta}$ represents the functional form for $\triangle \mathrm{AOD}_{\mathrm{fit}}$.

$\delta_{g, \theta}(\lambda)=\frac{\beta_{0}(\lambda)}{m_{\mathrm{a}}(\theta)} \cdot\left[a_{0}(\lambda)+a_{1}(\lambda) \cdot g+a_{2}(\lambda) \cdot g^{2}\right]$ 

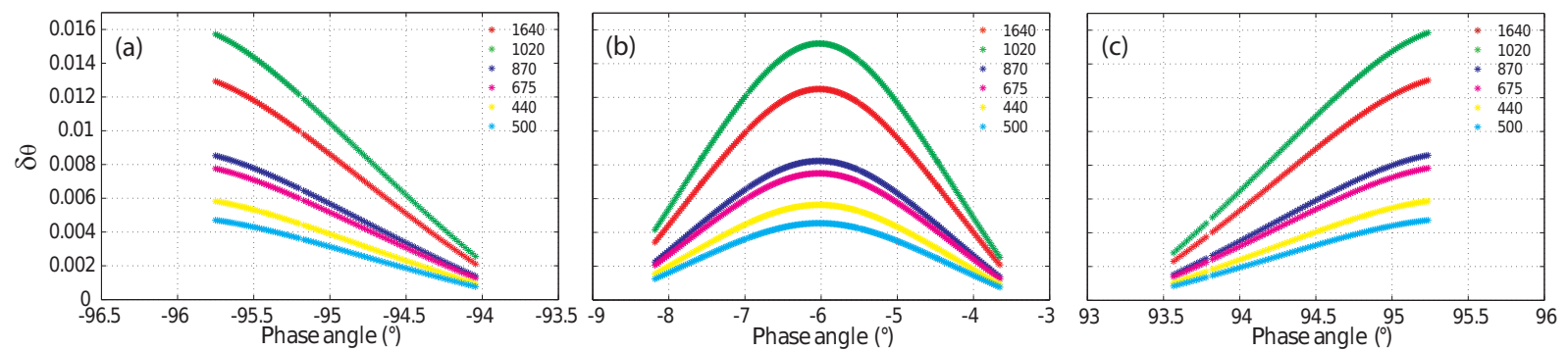

Figure 4. Predicted AOD differences from the fitting analysis with $\theta\left(\delta_{\theta}\right)$ for different phase angles: (a) 6 April, (b) 8 October and (c) 16 October.

The main results for this regression analysis, including simultaneously $g$ and $\theta$ dependences, are presented in Table 1 , in which we observe $R$-squared values ranging from 0.78 at $1020 \mathrm{~nm}$ to 0.60 at $440 \mathrm{~nm}$. These results indicate this fitted model is able to account for $\sim 78$ and $60 \%$ of the variation observed in $\triangle \mathrm{AOD}_{\text {fit }}$ for 1020 and $1640 \mathrm{~nm}$, respectively, which are the spectral bands more affected by the $g$ and $\theta$ dependence, within the $95 \%$ confidence bounds. RMSE values range from 0.009 at $1020 \mathrm{~nm}$ to 0.004 at $870 \mathrm{~nm}$, indicating a low variance of the residuals. In fact longer wavelength bands show higher RMSEs because they are more sensitively affected by this dependence. In this respect we observe that this empirical model is able to reproduce the asymmetry with phase angle, which is especially notable in the case of $1020 \mathrm{~nm}$. The total error sum of squares (SSE) of this fitting analysis are 0.19 for $1020 \mathrm{~nm}$ and below 0.10 for the rest of bands. This fitting analysis can be used to define a corrected nighttime $\mathrm{AOD}\left(\mathrm{AOD}_{\text {corr }}\right)$ as the addition of the measured $\mathrm{AOD}\left(\mathrm{AOD}_{\text {night }}\right)$ and $\delta_{g, \theta}\left(\mathrm{AOD}_{\text {corr }}=\mathrm{AOD}_{\text {night }}+\delta_{g, \theta}\right)$. The scatterplot between $\delta_{g, \theta}$ and $\triangle \mathrm{AOD}_{\text {fit }}$ is shown in Fig. 5, where a good agreement between parameterized and measured differences is found in the case of shorter wavelengths $(\lambda \leq 870 \mathrm{~nm})$. The more important differences were retrieved for the $1020 \mathrm{~nm}$ spectral band. We attribute the two branches above and below the horizontal line to a systematic error in our empirical model, which reproduces an amplified phase angle dependence in this 1020 spectral band. This effect is less appreciable but still discernible for $1640 \mathrm{~nm}$. The points above the diagonal correspond to overcorrected AOD values. It happens for high and positive phase angles. On the contrary, the points below the diagonal line represent those conditions poorly corrected, which happens for high and negative phase angles. Finally, the third branch with $\delta_{g, \theta}$ values up to 0.09 is observed for high and positive phase angles in some days in October and November 2014. We suspect that instrumental problems are behind such overcorrection cases.

We have performed an AOD day-night-day transition coherence test at Izaña in order to check this correction procedure. In this test we have compared nocturnal (CE318-T master) and daytime (CE318-N AERONET master) AOD corresponding to the consecutive $1 \mathrm{~h}$ time period during moonsetsunrise and sunset-moonrise in those 59 day-night-day tran-

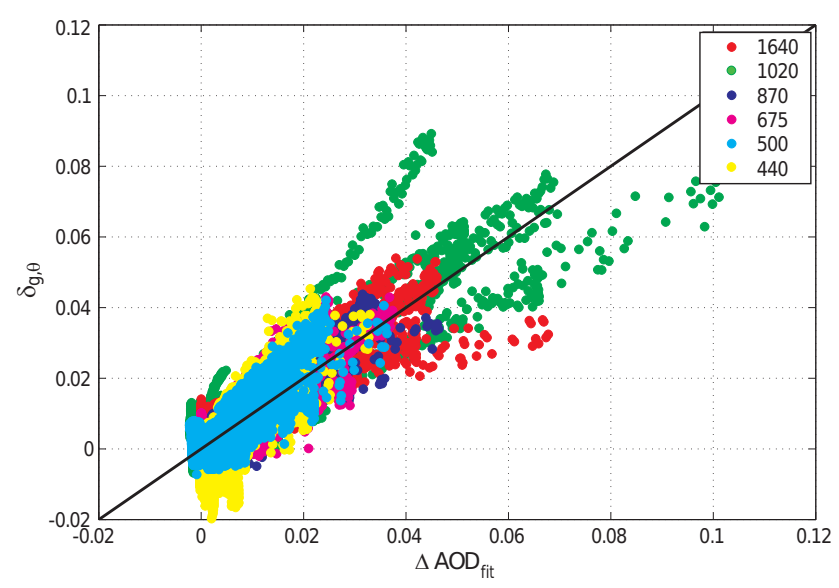

Figure 5. Scatterplot with parameterized $\left(\delta_{g, \theta}\right)$ and measured $\left(\triangle \mathrm{AOD}_{\mathrm{fit}}\right) \mathrm{AOD}$ differences. Solid line is the diagonal $(y=x)$.

sitions in 2014 classified as stable in terms of aerosol loads. In this test analysis $\triangle \mathrm{AOD}_{\text {trans }}$ represents the AOD difference between $1 \mathrm{~h}$ of Sun and Moon data. $\triangle \mathrm{AOD}_{\text {trans }}$ before and after correction for phase angles ranging from -100 to $100^{\circ}$ is presented in Fig. 6 and Table 2 for the six channels. We have verified the reduction in the systematic errors of $\triangle \mathrm{AOD}_{\text {trans }}$ after the correction, even though some problems of overcorrection are detected in the case of $1020 \mathrm{~nm}$ for $g>50^{\circ}$ and $500 \mathrm{~nm}$ for $g<-50^{\circ}$. AOD correction near full Moon is very low, as we expected from Eq. (5). We have found AOD differences within \pm 0.01 after correction for any illumination condition, below the instrumental precision expected for the CE318-T photometer (Barreto et al., 2016). This nocturnal AOD improvement is also evident in Fig. 7, especially for longer wavelength channels at low illumination conditions.

Finally, we present in Table 3 the mean AOD difference after and before the AOD correction ( $\triangle \mathrm{AOD})$ in the 59-night AOD-stable period in 2014 at Izaña as a function of phase angle. These differences are below 0.01 in the case of nearfull-Moon conditions but higher in the case of low illumination conditions: up to 0.04 and 0.03 for 1020 and $1640 \mathrm{~nm}$, respectively, and below 0.018 in the rest of channels. These 
Table 1. Results of $\triangle \mathrm{AOD}_{\text {fit }}$ parameterization for each channel: model coefficients, coefficient of determination $(R$ squared $)$ and root-meansquared error (RMSE) within $95 \%$ confidence bounds.

\begin{tabular}{lrrrrrr}
\hline $\begin{array}{l}\text { Channel } \\
(\mathrm{nm})\end{array}$ & $a_{0}$ & $a_{1}$ & $a_{2}$ & $a_{3}$ & $R$ squared & RMSE \\
\hline 1640 & 0.1260 & 0.0441 & 0.0040 & 0.0017 & 0.64 & 0.007 \\
1020 & -0.7311 & -0.8115 & -0.0220 & -0.0004 & 0.78 & 0.009 \\
870 & -0.0917 & -0.0919 & -0.0062 & -0.0007 & 0.78 & 0.004 \\
675 & -0.0260 & -0.0132 & -0.0174 & -0.0002 & 0.71 & 0.005 \\
500 & -0.0022 & -0.0001 & -0.0001 & -0.9755 & 0.68 & 0.005 \\
440 & 0.0097 & 0.0155 & 0.0009 & 0.0037 & 0.60 & 0.006 \\
\hline
\end{tabular}

Table 2. Averaged AOD differences between CE318-AERONET daytime and CE318-T nighttime data $(\triangle \mathrm{AOD}$ trans $)$ during sunset-moonrise and moonset-sunrise in three ranges of the Moon's phase angles $(g)$ with and without $\delta_{g, \theta}$ correction.

\begin{tabular}{lclrrrrrr}
\hline$g$ range & No. of cases & Correction & 1640 & 1020 & 870 & 675 & 500 & 440 \\
\hline \multirow{2}{*}{$\leq-50^{\circ}$} & \multirow{2}{*}{39} & no & 0.024 & 0.019 & 0.017 & 0.014 & 0.011 & 0.010 \\
& & yes & 0.008 & 0.007 & 0.007 & -0.003 & -0.005 & -0.003 \\
\hline \multirow{2}{*}{$-50^{\circ}>{ }^{\circ}>50^{\circ}$} & \multirow{2}{*}{81} & no & 0.011 & -0.003 & 0.008 & 0.007 & 0.005 & 0.002 \\
& & yes & 0.008 & -0.001 & 0.006 & 0.005 & 0.004 & 0.002 \\
\hline \multirow{2}{*}{$\geq 50^{\circ}$} & \multirow{2}{*}{26} & no & 0.022 & 0.025 & 0.014 & 0.013 & 0.010 & 0.010 \\
& & yes & 0.002 & -0.006 & 0.001 & 0.002 & -0.001 & 0.001 \\
\hline
\end{tabular}

results indicate the successful AOD correction, especially in longer wavelength channels, and the effective correction of the asymmetries through the Moon's cycle.

It is worth mentioning $\delta_{g, \theta}$ could be introduced in Eq. (1) to obtain $\mathrm{AOD}_{\text {corr }}$, and therefore $\delta_{g, \theta}$ could be subsequently used to define an $I_{0}$ correction only dependent on the Moon's phase angle $\left(I_{0}^{\prime}=I_{0} / \delta_{g}\right)$.

\subsection{Evaluation of the AOD correction at Izaña}

We have carried out the validation of the AOD correction presented ( $\delta_{g, \theta}$ in Eq. (5) with the coefficients in Table 1) using nighttime AOD extracted from the CE318-T master at Izaña in the period from June to August, 2016. This is a 43-night period which includes pristine conditions and some dust outbreaks with a maximum AOD at $500 \mathrm{~nm}$ of 0.61 (June, 2016). This period is suitable for assessing the AOD correction in a time period different than that used to parameterize the correction empirical model (parameterization period) and at different AOD loads. Similar results were observed in this case (see Table 4), with average AOD differences (after and before correction) up to $0.037(1020 \mathrm{~nm})$ and $0.023(1640 \mathrm{~nm})$ in the case of low illumination conditions and below 0.016 in the rest of spectral bands. We have observed again, as in the parameterization period in 2014, a considerable reduction in the $g$ and $\theta$ dependence on AOD after correction.

\subsection{Evaluation of the AOD correction at other sites: Carpentras, Dakar and Lille}

As a complementary validation analysis, we have extended the implementation of the previous correction procedure to three other test sites affected by different aerosol conditions. We have applied to the nocturnal AOD obtained at these other sites the same AOD correction ( $\delta_{g, \theta}$ in Eq. 5) with the same coefficients presented in Table 1, in order to ensure the validity of this empirical model to sites with quite different aerosols content. Carpentras $\left(44^{\circ} 4^{\prime} \mathrm{N}, 5^{\circ} 3^{\prime} \mathrm{E} ; 100 \mathrm{~m}\right.$ a.s.l. $)$ and Lille $\left(50^{\circ} 36^{\prime} \mathrm{N}, 3^{\circ} 8^{\prime} \mathrm{E}\right.$; $60 \mathrm{~m}$ a.s.l. $)$ are two calibration sites located in France. Both sites are affected by relatively low AOD conditions and fine mode particles as the dominant aerosol size distribution (average AOD at $500 \mathrm{~nm}$ of 0.14 and 0.19 , respectively, and average Ångström exponent of 1.4 and 1.2, respectively). In contrast, the station located in Dakar (M'Bour, Senegal; $14^{\circ} 23^{\prime} \mathrm{N}, 16^{\circ} 57^{\prime} \mathrm{W}$; 0 m a.s.1.) presents a significant contribution of marine aerosols and biomass burning aerosols during the dry season but also mineral dust with maximum influence in summer (Léon et al., 2009). In this case the averaged AOD at $500 \mathrm{~nm}$ and Ångström exponent are 0.45 and 0.37 , respectively, indicating the predominant coarse-mode aerosol at this station.

We have used nocturnal CE318-T AOD data at Carpentras in a 9-night period from 15 to 24 February 2016, a 10-night period at Dakar from 18 to 29 April 2016 and a 12-night period at Lille from 13 to 28 April 2016. These three instruments have been calibrated using the lunar Langley cal- 
Table 3. Average AOD difference between corrected and non-corrected AOD ( $\triangle \mathrm{AOD}$ ) measured at the Izaña station as a function of the Moon's phase angle $(g)$ in degrees in a 59-night period transition coherence test in 2014. The umber of nighttime measurements $(N)$ is included.

\begin{tabular}{lrrrrrrr}
\hline$g$ range & $N$ & 1640 & 1020 & 870 & 675 & 500 & 440 \\
\hline$\leq-50^{\circ}$ & 891 & 0.020 & 0.015 & 0.012 & 0.014 & 0.008 & 0.008 \\
$-50^{\circ}>g>50^{\circ}$ & 5076 & 0.003 & 0.003 & 0.002 & 0.002 & 0.001 & 0.001 \\
$\geq 50^{\circ}$ & 1030 & 0.026 & 0.041 & 0.018 & 0.014 & 0.014 & 0.013 \\
\hline
\end{tabular}

Table 4. Average AOD difference between corrected and non-corrected AOD ( $\triangle$ AOD) measured at four different stations in 2016. The number of nighttime measurements $(N)$ is included.

\begin{tabular}{llrrrrrrr}
\hline$g$ range & station & $N$ & 1640 & 1020 & 870 & 675 & 500 & 440 \\
\hline \multirow{2}{*}{$\leq-50^{\circ}$} & Izaña & 870 & 0.016 & 0.011 & 0.010 & 0.012 & 0.006 & 0.006 \\
& Carpentras & 350 & 0.021 & 0.015 & 0.013 & 0.015 & 0.008 & 0.009 \\
& Lille & 55 & 0.015 & 0.009 & 0.010 & 0.011 & 0.005 & 0.006 \\
& Dakar & 0 & - & - & - & - & - & - \\
\hline \multirow{2}{*}{$50^{\circ}>g>50^{\circ}$} & Izaña & 3459 & 0.003 & 0.004 & 0.002 & 0.002 & 0.001 & 0.001 \\
& Carpentras & 660 & 0.003 & 0.001 & 0.002 & 0.002 & 0.001 & 0.001 \\
& Lille & 423 & 0.003 & 0.001 & 0.002 & 0.002 & 0.001 & 0.001 \\
& Dakar & 527 & 0.002 & 0.002 & 0.002 & 0.002 & 0.001 & 0.001 \\
\hline \multirow{2}{*}{$50^{\circ}$} & Izaña & 631 & 0.023 & 0.037 & 0.016 & 0.012 & 0.012 & 0.011 \\
& Carpentras & 0 & - & - & - & - & - & - \\
& Lille & 7 & 0.011 & 0.018 & 0.008 & 0.006 & 0.006 & 0.005 \\
& Dakar & 31 & 0.020 & 0.033 & 0.014 & 0.010 & 0.010 & 0.010 \\
\hline
\end{tabular}

ibration technique at Izaña. AOD differences after and before correction $(\triangle \mathrm{AOD})$ for these three stations are quantified in Table 4 and displayed for different phase angles in Fig. 8 (only for 1640, 1020 and $440 \mathrm{~nm}$, to improve visualization). We found $\triangle \mathrm{AOD}$ values similar to those obtained for Izaña between 0.021 (1640 nm in Carpentras) and 0.005 $\left(500 \mathrm{~nm}\right.$ in Lille) in the case of phase angle $g \leq-50^{\circ}$, below 0.01 in the case of near-full-Moon conditions and ranging from 0.033 (1020 nm in Dakar) to $0.010(675,500$ and $440 \mathrm{~nm}$ in Dakar) for $g \geq 50^{\circ}$. It is worth mentioning that we have observed at these three stations a similar asymmetry of $\triangle \mathrm{AOD}$ with the Moon's cycle previously detected at Izaña, in which AOD differences are higher for $1020 \mathrm{~nm}$ in the case of high and positive phase angles (see Fig. 8b) while maximum differences are observed at $1640 \mathrm{~nm}$ when phase angle $g$ is strongly negative (see Fig. 8a and c). These results corroborate the existence of a residual phase angle dependence on nocturnal AOD and also exhibit a similar-in-magnitude zenith angle dependence to the one observed at Izaña, discarding the instrumental problem as the source of these errors. This evaluation analysis at different stations seems to corroborate that this correction procedure is applicable to other instruments and sites. However, it is fair to admit that this correction has been performed by means of an unique instrument, with certain optical interference filters. The difference in the filter responses as well as the degradation of optical filters with time are the limiting factors. They could add an extra uncertainty depending on the different band responses between instruments. Further studies will be focused on the estimation of this extra uncertainty.

\section{Conclusions}

The comparison of the CE318-T calibration performed by means of the lunar Langley calibration and the calibration performed every single night by means of the common Langley technique indicates the existence of some systematic errors on ROLO's lunar irradiances. These systematic errors could have an important impact on the AOD retrieved by means of lunar photometry. In order to reduce the uncertainties in the AOD retrieved at nighttime using a calibration technique dependent on this lunar irradiance model (the lunar Langley and the intercomparison techniques "ratio Sun" and "ratio Moon"), we have studied the evolution of the AOD at nighttime at the Izaña high mountain observatory in a period characterized as clean and stable. These conditions were ensured by means of vertical profiles from an MPL-3 lidar installed at a nearby coastal station as well as by means of an AOD stability criterion using daytime AERONET data. We detected an important bias correlated to the Moon's phase and zenith angles ( $g$ and $\theta$ ) in all the spectral bands. However, the important phase angle dependence found for 1020 

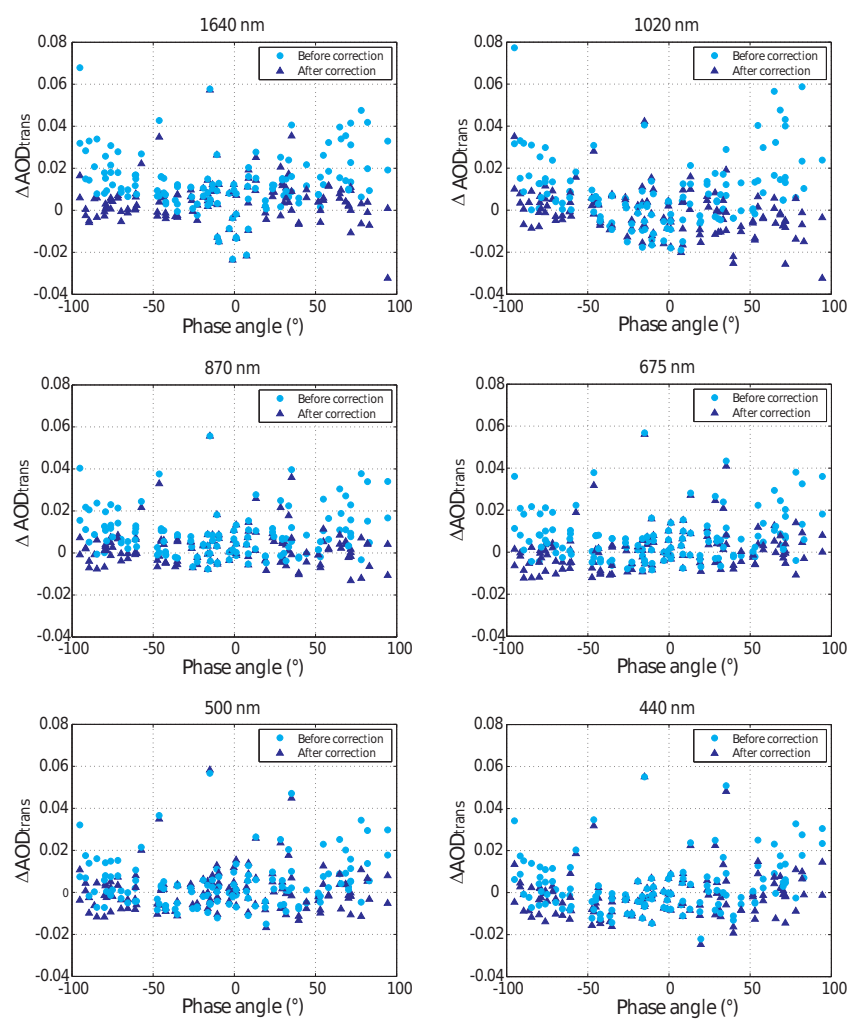

Figure 6. AOD differences with the Moon's phase angle in the AOD day-night transition coherence test between daytime CE318$\mathrm{N}$ AERONET AOD and CE318-T nighttime AOD during sunsetmoonrise and moonset-sunrise period before (circles) and after (triangles) the AOD correction.
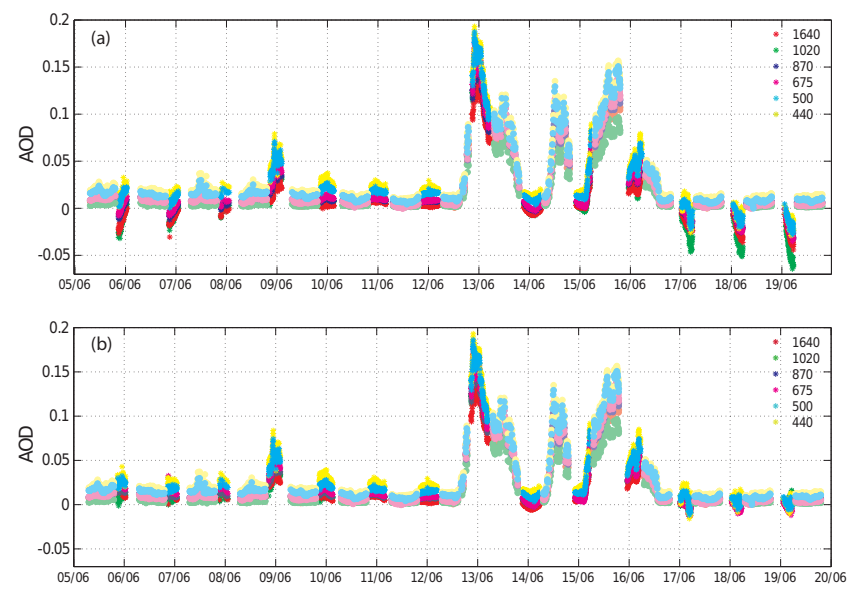

Figure 7. AOD evolution for one Moon cycle (June 2014) at Izaña. Opaque colors represent daylight data. Nocturnal AOD before (a) and after (b) correction is plotted.

and $1640 \mathrm{~nm}$ might be an artifact caused by a systematic error in our empirical model. Working under stable AOD conditions, we have parameterized this residual dependence in nocturnal AOD in terms of the Moon's phase and zenith an-
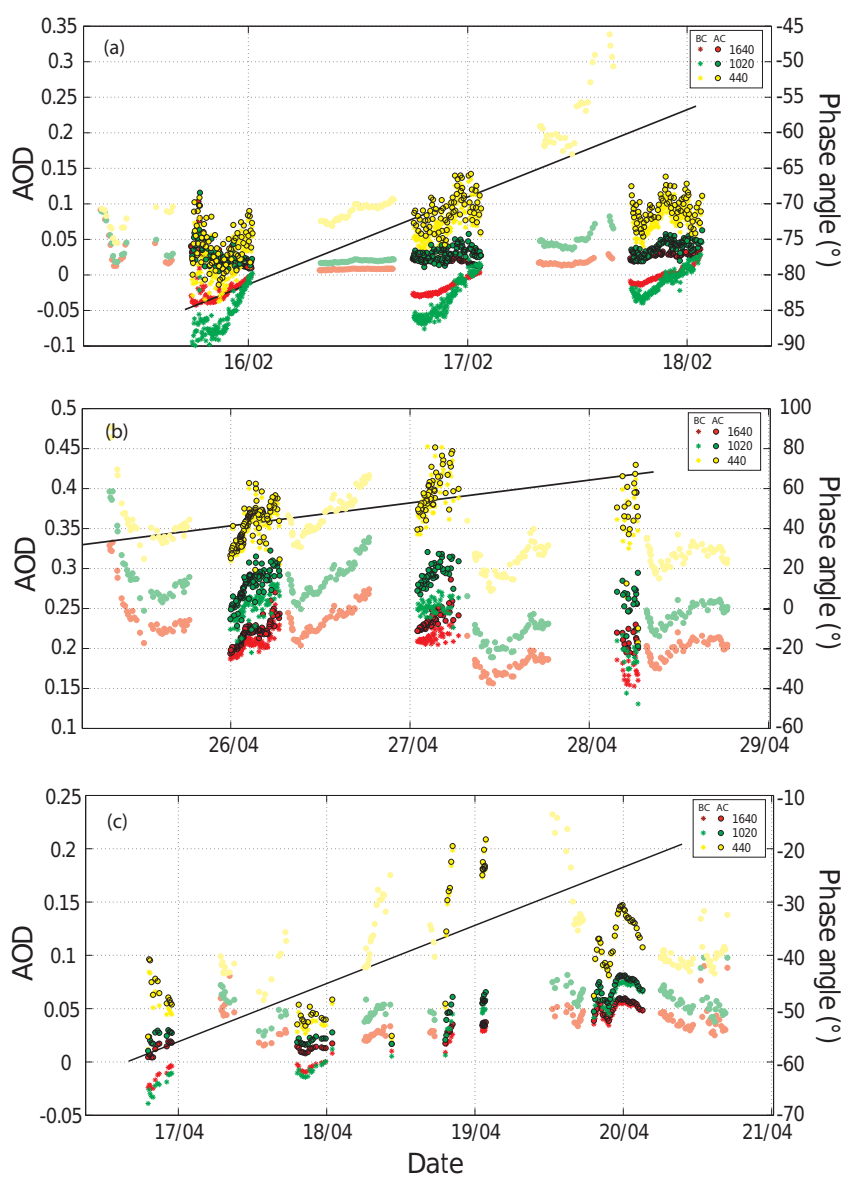

Figure 8. AOD before correction (BC) and after correction (AC) at (a) Carpentras, (b) Dakar and (c) Lille in 2016. Opaque colors represent daylight data. The black line and right $y$ axis correspond to the phase angle evolution in this period.

gles through an empirical regression model. Our results show AOD at nighttime is significantly corrected, with absolute errors $<0.01$, i.e., below the instrument precision, in spite of the absence of a robust cloud screening system.

We attribute the phase angle dependence on AOD residuals to the inherent limitations of the ROLO model. The nocturnal cycle observed in AOD with a $g$-dependent amplitude could be related to the existence of a propagation of systematic calibration errors as a result of the use of a biased irradiance model for calibration (performed under high illumination conditions) and its subsequent use for AOD calculation. As a result, the use of a biased model during the lunar Langley calibration unavoidably introduces systematic calibration uncertainties that should be corrected using the empirical equations proposed in this study. The authors would like to admit that this is only a preliminary AOD correction proposal developed using one single instrument which might be refined and used to correct the lunar irradiance model in future studies. Since long-term lunar observations are required for an accurate modeling of the Moon's phase and librations 
effects, several years of lunar measurements are required to perform an adequate correction, in terms of both AOD or $I_{0}$. In this respect, we strongly recommend the use of the unique calibration method independent of any lunar irradiance model: the Sun-Moon gain factor method, proposed by Barreto et al. (2016). Further investigations will be carried out to check the suitability of this technique for different locations and the Moon's illumination conditions.

It should be highlighted that in this study the authors only intend to correct the AOD retrieval at nighttime affected by these biases as much as possible. It is out of the scope of the present study to propose and perform corrections on the ROLO USGS model. This issue is beginning to be addressed thoroughly by several groups. An example is the Global Space-based Inter-Calibration System (GSICS) Lunar Observation Dataset (GLOD), which is a collaborative effort to use the Moon as a common and unique calibration reference at the international level. This database includes Moon observations from several space organizations such as the European Space Agency, the European Organization for the Exploitation of Meteorological Satellites (EUMETSAT), the National Centre for Space Studies (CNES), the Japan Aerospace Exploration Agency, the National Satellite Meteorological Center from the China Meteorological Administration (NSMCCMA), or the National Aeronautics and Space Administration, among others.

Data availability. ROLO model has been implemented using Eq. (10) in Kieffer and Stone (2005). Daytime aerosol optical depth data at four stations (Izaña, Dakar, Carpentras and Lille) are available from the AERONET website (https://aeronet.gsfc.nasa.gov/). CE318-T nighttime data are available upon request. The MPL-3 lidar data at the Santa Cruz station are also available upon request.

Competing interests. The authors declare that they have no conflict of interest.

Acknowledgements. This work has been developed within the framework of the activities of the World Meteorological Organization (WMO) Commission for Instruments and Methods of Observations (CIMO) Izaña test bed for aerosols and water vapor remote sensing instruments.

AERONET Sun photometers at Izaña have been calibrated within the AERONET Europe TNA, supported by the European Union's Horizon 2020 research and innovation program under grant agreement no. 654109 (ACTRIS-2). The authors also thank AERONET team for their support. The GAW-Precision Filter Radiometer network for AOD at WMO-GAW global observatories has been implemented by the World Optical Depth Research and Calibration Center (WORCC).

Edited by: Piet Stammes

Reviewed by: two anonymous referees

\section{References}

Baibakov, K., O’Neill, N. T., Ivanescu, L., Duck, T. J., Perro, C., Herber, A., Schulz, K.-H., and Schrems, O.: Synchronous polar winter starphotometry and lidar measurements at a High Arctic station, Atmos. Meas. Tech., 8, 3789-3809, https://doi.org/10.5194/amt-8-3789-2015, 2015.

Barreto, A., Cuevas, E., Damiri, B., Guirado, C., Berkoff, T., Berjón, A. J., Hernández, Y., Almansa, F., and Gil, M.: A new method for nocturnal aerosol measurements with a lunar photometer prototype, Atmos. Meas. Tech., 6, 585-598, https://doi.org/10.5194/amt-6-585-2013, 2013a.

Barreto, A., Cuevas, E., Damiri, B., Romero, P. M., and Almansa, F.: Column water vapor determination in night period with a lunar photometer prototype, Atmos. Meas. Tech., 6, 2159-2167, https://doi.org/10.5194/amt-6-2159-2013, 2013 b.

Barreto, Á., Cuevas, E., Granados-Muñoz, M.-J., AladosArboledas, L., Romero, P. M., Gröbner, J., Kouremeti, N., Almansa, A. F., Stone, T., Toledano, C., Román, R., Sorokin, M., Holben, B., Canini, M., and Yela, M.: The new sun-skylunar Cimel CE318-T multiband photometer - a comprehensive performance evaluation, Atmos. Meas. Tech., 9, 631-654, https://doi.org/10.5194/amt-9-631-2016, 2016.

Berkoff, T. A., Sorokin, M., Stone, T., Eck, T. F., Hoff, R., Welton, E., and Holben, B.: Nocturnal aerosol optical depth measurements with a small-aperture automated photometer using the moon as a light source, J. Atmos. Ocean. Tech., 28, 1297-1306, https://doi.org/10.1175/JTECH-D-10-05036.1, 2011.

Cachorro, V. E., Romero, P. M., Toledano, C., Cuevas, E., and de Frutos, A. M.: The fictitious diurnal cycle of aerosol optical depth: A new approach for "in situ" calibration and correction of AOD data series, Geophys. Res. Lett., 31, L12106, https://doi.org/10.1029/2004GL019651, 2004.

Cachorro, V. E., Toledano, C., Berjón, A. J., de Frutos, A. M., Sorribas, M.: Comment on "On Langley plots in the presence of a systematic diurnal aerosol cycle centered at noon: A comment on recently proposed methodologies" by F. Marenco, J. Geophys. Res., 113, D11210, https://doi.org/10.1029/2007JD009137, 2008a.

Cachorro, V. E., Toledano, C., Berjón, A. J., de Frutos, A. M., Torres, B., Sorribas, M., and Laulainen, N. S.: An "in situ" calibration correction procedure (KCICLO) based on AOD diurnal cycle: Application to AERONET-El Arenosillo (Spain) AOD data series, J. Geophys. Res., 113, D12205, https://doi.org/10.1029/2007JD009673, 2008b.

Campbell, J. R., Hlavka, D. L., Welton, E. J., Flynn, C. J., Turner, D. D., Spinhirne, J. D., Scott, V. S., and Hwang, I. H.: Full-time, Eye-Safe Cloud and Aerosol Lidar Observation at Atmospheric Radiation Measurement Program Sites: Instrument and Data Processing, J. Atmos. Ocean. Tech., 19, 431-442, https://doi.org/10.1175/15200426(2002)019<0431:FTESCA>2.0.CO;2, 2002.

Cramer, C. E., Lykke, K. R., Woodward, J. T., and Smith, A. W.: Precise measurements of lunar spectral irradiance at visible wavelengths, J. Res. Natl. Inst. Stan., 118, 396-402, https://doi.org/10.6028/jres.118.020, 2013.

Cuevas, E., González, Y., Rodríguez, S., Guerra, J. C., GómezPeláez, A. J., Alonso-Pérez, S., Bustos, J., and Milford, C.: Assessment of atmospheric processes driving ozone variations in the subtropical North Atlantic free troposphere, Atmos. 
Chem. Phys., 13, 1973-1998, https://doi.org/10.5194/acp-131973-2013, 2013.

Cuevas, E., Camino, C., Benedetti, A., Basart, S., Terradellas, E., Baldasano, J. M., Morcrette, J. J., Marticorena, B., Goloub, P., Mortier, A., Berjón, A., Hernández, Y., Gil-Ojeda, M., and Schulz, M.: The MACC-II 2007-2008 reanalysis: atmospheric dust evaluation and characterization over northern Africa and the Middle East, Atmos. Chem. Phys., 15, 3991-4024, https://doi.org/10.5194/acp-15-3991-2015, 2015.

Eck, T., Holben, B., Reid, J. S., Dubovik, O., Smirnov, A., O'Neill, N. T., Slutsker, I., and Kinne, S.: Wavelength dependence of the optical depth of biomass burning urban and desert dust aerosols, J. Geophys. Res., 104, 31333-31349, https://doi.org/10.1029/1999JD900923, 1999.

Eck, T. F., Holben, B. N., Reid, J. S., Sinyuk, A., Hyer, E. J., O’Neill, N. T., Shaw, G. E., Vande Castle, J. R., Chapin, F. S., Dubovik, O., Smirnov, A., Vermote, E., Schafer, J. S., Giles, D., Slutsker, I., Sorokine, M., and Newcomb, W. W.: Optical properties of boreal region biomass burning aerosols in central Alaska and seasonal variation of aerosol optical depth at an Arctic coastal site, J. Geophys. Res., 114, D11201, https://doi.org/10.1029/2008JD010870, 2009.

Eck, T. F., Holben, B. N., Sinyuk, A., Pinker, R. T., Goloub, P., Chen, H., Chatenet, B., Li, Z., Singh, R. P., Tripathi, S. N., Reid, J. S., Giles, D. M., Dubovik, O., O’Neill, N. T., Smirnov, A., Wang, P., and Xia, X.: Climatological aspects of the optical properties of fine/coarse mode aerosol mixtures, J. Geophys. Res., 115, D19205, https://doi.org/10.1029/2010JD014002, 2010.

Esposito, F., Serio, C., Pavesse, G., Auriemma, G., and Satriano, C.: Measurements of nighttime atmospheric optical depth. Preliminary data from mountain site in southern Italy, J. Aerosol Sci., 29, 1213-1218, 1998.

Esposito, F., Mari, S., Pavese, G., and Serio, C.: Diurnal and Nocturnal Measurements of Aerosol Optical Depth at a Desert Site in Namibia, Aerosol. Sci. Tech., 37, 392-400, https://doi.org/10.1080/02786820300972, 2003.

Forster, P., Ramaswamy, V., Artaxo, P., Berntsen, T., Betts, R., Fahey, D. W., Haywood, J., Lean, J., Lowe, D. C., Myhre, G., Nganga, J., Prinn, R., Raga, G., Schulz, M., and Van Dorland, R.: Changes in Atmospheric Constituents and in Radiative Forcing, in: Climate Change 2007: The Physical Science Basis. Contribution of Working Group I to the Fourth Assessment Report of the Intergovernmental Panel on Climate Change, edited by: Solomon, S., Qin, D., Manning, M., Chen, Z., Marquis, M., Averyt, K. B., Tignor, M., and Miller, H. L., Cambridge University Press, Cambridge, United Kingdom and New York, NY, USA, 2007.

Guirado, C.: Caracterización de las propiedades de los aerosoles en columna en la región subtropical, $\mathrm{PhD}$ thesis, Universidad de Valladolid, Valladolid, Spain, 2014.

Holben, B. N., Eck, T. F., Slutsker, I., Tanré, D., Buis, J. P., Setzer, A., Vermote, E., Reagan, J. A., Kaufman, Y. J., Nakajima, T., Lavenu, F., Jankowiak, I., and Smirnov A.: AERONET - A federated instrument network and data archive for aerosol characterization, Remote Sens. Environ., 66, 1-16, https://doi.org/10.1016/S0034-4257(98)00031-5, 1998.

Holben, B. N., Tanré, D., Smirnov, A., Eck, T. F., Slutsker, I., Abuhassan, N., Newcomb, W. W., Schafer, J., Chatenet, B., Lavenue, F., Kaufman, Y. J., Vande Castle, J., Setzer, A., Markham,
B., Clark, D., Frouin, R., Halthore, R., Karnieli, A., O’Neill, N. T., Pietras, C., Pinker, R. T., Voss, K., and Zibordi, G.: An emerging ground-based aerosol climatology: Aerosol Optical Depth from AERONET, J. Geophys. Res., 106, 12067-12097, https://doi.org/10.1029/2001JD900014, 2001.

IPCC: Climate Change 2013: The Physical Science Basis. Contribution of Working Group I to the Fifth Assessment Report of the Intergovernmental Panel on Climate Change, edited by: Stocker, T. F., Qin, D., Plattner, G.-K., Tignor, M., Allen, S. K., Boschung, J., Nauels, A., Xia, Y., Bex, V., and Midgley, P. M., Cambridge University Press, Cambridge, UK and New York, NY, USA, 33115, https://doi.org/10.1017/CBO9781107415324, 2013.

Kieffer, H. H. and Stone, T. C.: The spectral irradiance of the moon, The Astron. J., 129, 2887-2901, https://doi.org/10.1086/430185, 2005.

Lacherade, S., Viticchié, B., Stone, T., Lebégue, L., Wagner, S., and Hewison, T.: On the phase-angle dependence of the moon calibration results, GSICS Quat: Lunar calibration, 7, 6-7, 2013.

Lacherade, S., Aznay, O., Fougnie, B., and Lebégue, L.: POLO: a unique dataset to derive the phase angle dependence of the Moon irradiance, Proc. SPIE 9241, Sensors, Systems, and Next-Generation Satellites XVIII, 924112 (7 October 2014), https://doi.org/10.1117/12.2067283, 2014.

Leiterer, U., Naebert, A., Naebert, T., and Alekseeva, G.: A new star photometer developed for spectral aerosol optical thickness measurements in Lindenberg, Contrib. Atmos. Phys., 68, 133141, 1995.

Léon, J.-F., Derimian, Y., Chiapello, I., Tanré, D., Podvin, T., Chatenet, B., Diallo, A., and Deroo, C.: Aerosol vertical distribution and optical properties over M'Bour $\left(16.96^{\circ} \mathrm{W} ; 14.39^{\circ} \mathrm{N}\right)$, Senegal from 2006 to 2008, Atmos. Chem. Phys., 9, 9249-9261, https://doi.org/10.5194/acp-9-9249-2009, 2009.

Miller, S. D., Combs, C. L., and Kidder, S. Q.: Assessing Moonlight Availability for Nighttime Environmental Applications by Low-Light Visible Polar-Orbiting Satellite Sensors, J. Atmos. Ocean. Tech., 29, 538-557, https://doi.org/10.1175/JTECH-D11-00192.1, 2012.

Pérez-Ramírez, D., Lyamani, H., Olmo, F. J., Whiteman, D. N., Navas-Guzmán, F., and Alados-Arboledas, L.: Cloud screening and quality control algorithm for star photometer data: assessment with lidar measurements and with all-sky images, Atmos. Meas. Tech., 5, 1585-1599, https://doi.org/10.5194/amt-5-15852012, 2012.

Pérez-Ramírez, D., Veselovskii, I., Whiteman, D. N., Suvorina, A., Korenskiy, M., Kolgotin, A., Holben, B., Dubovik, O., Siniuk, A., and Alados-Arboledas, L.: High temporal resolution estimates of columnar aerosol microphysical parameters from spectrum of aerosol optical depth by linear estimation: application to long-term AERONET and star-photometry measurements, Atmos. Meas. Tech., 8, 3117-3133, https://doi.org/10.5194/amt-83117-2015, 2015.

Rodríguez, S., Alastuey, A., Alonso-Pérez, S., Querol, X., Cuevas, E., Abreu-Afonso, J., Viana, M., Pérez, N., Pandolfi, M., and de la Rosa, J.: Transport of desert dust mixed with North African industrial pollutants in the subtropical Saharan Air Layer, Atmos. Chem. Phys., 11, 6663-6685, https://doi.org/10.5194/acp11-6663-2011, 2011. 
Shaw, G. E.: Error analysis of multi-wavelength Sun photometry, Pure Appl. Geophys., 114, 1-14, https://doi.org/10.1007/BF00875487, 1976.

Shaw, G. E.: Sun photometry, B. Am. Meteorol. Soc., 64, 4-10, https://doi.org/10.1175/15200477(1983)064<0004:SP>2.0.CO;2, 1983.

Viticchié, B., Wagner, S., Hewison, T., and Stone, T.: Lunar calibration of MSG/SEVIRI solar bands, GSICS Quat: Lunar calibration, 7, 3-5, 2013.
Wehrli, C.: Spectral Solar Irradiance Data (WMO ITD 149; Geneva: WMO), 1986.

Welton, E. J. and Campbell, J. R.: Micro-pulse lidar signals: Uncertainty analysis, J. Atmos. Ocean. Tech., 19, 2089-2094, https://doi.org/10.1175/15200426(2002)019<2089:MLSUA>2.0.CO;2, 2002. 